\title{
Uso e ocupação do solo no município de Cristal/RS
}

O conhecimento do uso e ocupação do solo de um município é de extrema importância para o planejamento municipal e ambiental, com o auxílio das geotecnologias pode-se ter mais segurança técnica nas tomadas de decisões referente aos processos a serem aprovados e também na elaboração de projetos para a própria gestão pública. Neste artigo o objeto de pesquisa foi o município de Cristal, região de atividades de mineração, às margens do Rio Camaquã e que apresenta uma série de ocupações irregulares. No qual o objetivo foi o mapeamento do usos e ocupações do solo e a correlação com os recursos naturais do município. Para tal utilizou-se a imagem do sensor MUX da plataforma CBERS 4 nos programas livres MultiSpec para classificação, analise e Quantum GIS (QGIS) para e confecção de mapa de uso e cobertura do solo do Município de Cristal/RS. Como resultado da classificação pelo método MaxVer podemos observar que os resultados foram significativos sendo $66,14 \%$ da área do município de áreas identificadas para classe campo/agricultura, 18,80 \% para a classe vegetação nativa, $6,18 \%$ identificado como a Classe Solo exposto, 6,03 \% composta de vegetação exótica e 2,83 \% como água.

Palavras-chave: Gestão Pública; Geotecnologias; Uso e Ocupação do Solo.

\section{Use and occupation of soil in the city of Cristal/RS}

The knowledge of the use and occupation of the soil of a municipality is of extreme importance for the municipal and environmental planning, with the help of the geotechnologies one can have more technical security in the decision making regarding the processes to be approved and also in the elaboration of projects for its own public management. In this article the object of research was the municipality of Cristal, a region of mining activities, on the banks of the Camaquã River, which presents a series of irregular occupations. In which the objective was the mapping of the uses and occupations of the soil and the correlation with the natura resources of the municipality. In order to do so, we used the image of the MUX sensor of the CBERS 4 platform in the free MultiSpec programs for classification, analysis and Quantum GIS (QGIS) for the construction of the use map and soil cover of the Municipality of Cristal/RS. As a result of the MaxVer classification we can observe that the results were significant, being $66.14 \%$ of the area of the municipality identified for the field / agriculture class, $18.80 \%$ for the native vegetation class, $6.18 \%$ identified as the Class Exposed soil, 6.03\% composed of exotic vegetation and $2.83 \%$ as water.

Keywords: Public Management; Geotechnology; Use and Occupation of Soil.

Topic: Planejamento, Gestão e Políticas Públicas Ambientais

Reviewed anonymously in the process of blind peer.
Received: 10/02/2019

Approved: 25/03/2019
Daniel Britto dos Santos (iv

Universidade Federal de Pelotas, Brasil

http://lattes.cnpq.br/6021088115532079

http://orcid.org/0000-0003-4430-6055

daniel@perolaambiental.com

Daiane Kath Dallmann (iD

Universidade Federal de Pelotas, Brasil

http://lattes.cnpq.br/5296562263340120

http://orcid.org/0000-0002-6222-6430

daiane@perolaambiental.com

Diuliana Leandro (ic

Universidade Federal de Pelotas, Brasil

http://lattes.cnpq.br/3076528365846421

http://orcid.org/0000-0002-8092-5550

diuliana.leandro@gmail.com
Referencing this:

SANTOS, D. B.; DALLMANN, D. K.; LEANDRO, D.. Uso e ocupação do solo no município de Cristal/RS. Revista Ibero Americana de Ciências Ambientais, v.10, n.2, p.340-350, 2019. DOI:

http://doi.org/10.6008/CBPC2179-6858.2019.002.0028 


\section{INTRODUÇÃO}

Quando se fala em gestão e planejamento público é essencial se conhecer o município, entender a distribuição do uso do solo e fenômenos sociais e ambientais sobre essa região para a definição de ações e tomada de decisões. Julião (2014), ressalta que na definição de gestão se dá particular destaque à necessidade de esta ser um conjunto de tomada de decisões racionais e fundamentadas na aquisição e tratamento de dados e informações relevantes, e que para uma boa gestão pressupõe boa informação: atual e confiável. De acordo com Pessoa et al. (2018), cadastros territoriais e mapeamentos com bases atualizadas e confiáveis fornecem dados econômicos, sociais e ambientais que podem potencializar a atuação do planejamento territorial, além de ampliar a arrecadação e gerar novas receitas. Esse entendimento permite que toda decisão aconteça de forma eficiente baseada em parâmetros reais de modo a minimizar custos, otimizar recursos humanos, financeiros e tecnológicos, minimizando dessa forma os erros nesse processo. É primordial considerar que o ambiente de decisão é dinâmico, tornando o processo complexo e continuo. Nesse contexto, as geotecnologias contribuírem consideravelmente para o ordenamento territorial, o gerenciamento, o controle do parcelamento, o uso e a ocupação do solo urbano municipal.

Nesta situação, o sensoriamento remoto, por meio de sensores orbitais fornecem dados com que possibilitam produzir informações da cobertura e uso da terra, sem entrar em contato físico com os objetos ou fenômenos (JENSEN, 2011), permitindo indicar a distribuição geográfica das tipologias de uso, possibilitando a posterior criação de mapas temáticos com o uso subdividido em classes, tais como: vegetação arbórea, vegetação rasteira, solo exposto, área urbana, entre outras. Desse modo, as imagens propiciam mapeamentos detalhados, de áreas espacialmente contíguas, permitindo comparações das variações do uso do solo multitemporais e com cenários complexos comparáveis, pois o conhecer e entender a distribuição do uso da terra é importante para os administradores públicos definirem políticas e ações adequadas para sua utilização. Assim os mapas temáticos são extremamente úteis para gerenciamento, controle, cadastramento e acompanhamento da dinâmica e comportamento dos objetos e fenômenos inerentes às áreas estudadas, permitindo aos gestores públicos a tomada de decisão de forma rápida e acertada. Aponta-se como vantagem dessas técnicas de interpretação automática de imagens o aumento da produtividade e precisão do trabalho, bem como a redução da subjetividade do resultado (CAMARGO et al., 2012).

A expressão 'uso e cobertura do solo' é um conceito híbrido, formado por três conceitos: uso, cobertura e solo. O primeiro termo diz respeito ao que o homem constrói ou insere sobre a superfície ou como maneja o solo com agricultura, pastagens, cidades, entre outros, enquanto o segundo se refere aos atributos físicos da superfície terrestre como florestas, campos, desertos, etc. (ALVES, 2004) e o terceiro é a camada superficial da crosta terrestre oriundo da decomposição da rocha-matriz, sob influência do clima e de processos físicos, químicos e biológicos, no qual os vegetais se desenvolvem (FLORES et al., 1999).

As imagens de satélite para serem manipuladas, analisadas, classificadas e integradas com outros dados espaciais dependem de programas, que possuam ferramentas adequadas para o processamento e 
manipulação, e esses podem ser tanto comerciais quanto livres. Geralmente a utilização de softwares proprietários onera os trabalhos de profissionais que realizam análise de imagens de satélite e impede o acesso ao código fonte do programa (STEINIGER et al., 2009). Os avanços tecnológicos vêm disponibilizando alguns programas livres, os quais vêm sendo testados e aperfeiçoados, como por exemplo o Quantum GIS (QGIS), que frequentemente lança atualizações gratuitas, e o MultiSpec. Ambos permitem a classificação de imagens, porém, além disso, o QGIS permite análises com um número maior de parâmetros ambientais, possibilitando a integração com dados complementares (vetoriais), pois ele é um Sistema de Informações Geográficas (SIGs). Segundo Câmara et al. (1998) os SIGs consistem em ferramentas computacionais que permitem realizar análises complexas, ao integrar dados de diversas fontes e ao possibilitar criar bancos de dados georreferenciados, tornando ainda possível automatizar a produção de documentos cartográficos. Essas ferramentas permitem que de maneira eficaz possamos identificar os usos das áreas dos municípios, podendo dar subsídios para elaboração ou atualização de leis referente aos usos e ocupação das mesmas.

Neste contexto, definimos como área de estudo o município de Cristal, o qual possui organização do espaço urbano com grande influência de atividades de mineração, responsável pela geração de empregos através de extração de areia e argila, atividade que vêm acelerando a expansão a aglomeração urbana. 0 município de Cristal se situa às margens do Rio Camaquã que sofre com assoreamento devido os usos e ocupações do solo de maneira indevida. Considerando essas problemáticas e a hipótese de que são geradas pelo uso e ocupação do solo indevido das atividades de mineração, neste trabalho propõem-se a identificação dos usos e ocupações do solo no município de Cristal e a discussão sobre a sua influência nos recursos naturais do município, possibilitando que o produto dessas análises forneça subsídios para a implementação de políticas públicas.

\section{MATERIAIS E MÉTODOS}

\section{Área de estudo}

O Município está localizado à beira da BR 116, o que garante facilidade de acesso, pois dista aproximadamente $150 \mathrm{~km}$ de Porto Alegre e $100 \mathrm{~km}$ de Pelotas. Conforme IBGE (2010), em 2017 a população estimada do município era de 7.831 habitantes. Com área total de $655 \mathrm{Km}^{2}$, o município de Cristal faz divisa ao norte, com o município de Camaquã e Amaral Ferrador; ao sul com São Lourenço do Sul; ao leste com São Lourenço do Sul e Camaquã; ao oeste, com São Lourenço do Sul e Canguçu (CRISTAL, 2008), como pode ser observado na figura 1.

A maior parte dos solos do município tem origem a partir do granito, resultando em elevados teores de areia grossa. Observa-se a topossequência, ou seja, uma sequência de solos que pode ser observado em uma encosta, Argissolo Vermelho Amarelo - Planossolo Hidromórfico, enquanto o Neossolo Flúvico ocorre nas áreas costeiras dos cursos d'água (CRISTAL, 2011). O município de Cristal não possui Lei atual que disciplina o uso e ocupação do solo, possui apenas a Lei $n^{\circ} 1238$ de 21/11/2011 que dispõe sobre o 
parcelamento do solo urbano e dá outras providências, que regra o parcelamento do solo urbano, que trata exclusivamente de usos para fins de loteamentos.

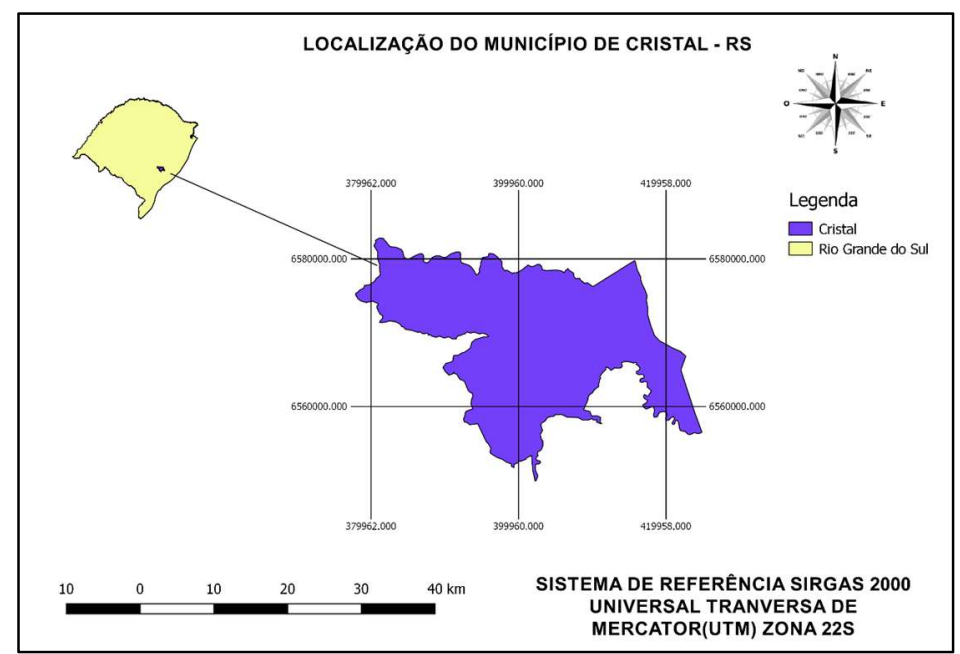

Figura 1: Localização do município de Cristal/RS.

Para o desenvolvimento deste trabalho, foram utilizados dados matriciais do sensor MUX do satélite CBERS 4, que de acordo com o INPE (2018), possui resolução espacial de $20 \mathrm{~m}$, resolução radiométrica de 8bits, com 4 bandas espectrais que abrangem a faixa do espectro magnético: de 0,45-0,52 $\mu \mathrm{m}$ para a banda

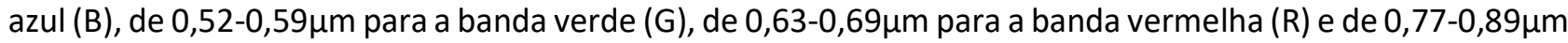
para a banda do infravermelho próximo (NIR). As imagens CBERS 4 são oriundas do Programa CBERS que nasceu de uma parceria inédita entre Brasil e China no setor técnico-científico espacial (INPE, 2018). ${ }^{1}$

Para o processo de classificação de imagens utilizou-se o software MultiSpec, versão 3.6, que segundo Rodríguez (2018), um software gratuito, considerado simples de utilizar e que possui muitas ferramentas aplicáveis a qualquer tipo de imagem para a qual deseja-se realizar análises multiespectrais, fornecendo bons resultados. De acordo com a Purdue Research Foundation (2018), da Universidade Purdue, West Lafayette, IN, o MultiSpec foi desenvolvido por David Landgrebe e Larry Biehl, com o objetivo de proporcionar uma tecnologia robusta e fundamental para a análise de dados de imagem hiperespectral e multiespectral, transferindo essa tecnologia para a comunidade de usuários da maneira mais rápida possível. As análises quantitativas e geração de mapas temáticos foram realizados através do software Quantum Gis - QGIS, versão 2.18.12, programa livre e de código aberto, um SIG que permite abrir mapas digitais, realizar análises espaciais e assim criar informações.

Para o desenvolvimento desta pesquisa utilizou-se os procedimentos metodológicos sequenciais indicados na Figura 2. A realização do estudo iniciou com a seleção de imagens de satélite do catálogo de imagens do INPE (Instituto Nacional de Pesquisas Espaciais), considerando as imagens que recobrem o município apresentem datas similares e possuam baixo recobrimento de nuvens sobre a área de interesse. Após o download realizou-se a junção das 4 bandas do sensor MUX e verificou-se a ocorrência de deslocamento da imagem através do complemento OpenLayers Plugin no QGIS, o qual segundo Layers

\footnotetext{
${ }^{1}$ Essas imagens são gratuitas e disponibilizadas através do Catálogo de Imagens do INPE no link http://www.dgi.inpe.br/catalogo/.
} 
(2018), é uma ferramenta que permite usar as imagens de satélite de qualquer local no globo de forma gratuita para pesquisas e ensino.

As imagens do satélite CBERS 4, que inicialmente apresentavam-se no sistema de referência WGS84, foram projetadas para o sistema Universal Transverso de Mercator - UTM, fuso $22 \mathrm{~S}$ e o Sistema Geodésico Sirgas 2000. Sequencialmente definiu-se o número e as classes que seriam utilizadas no estudo. No MultiSpec versão 3.6 realizou-se a classificação de imagens digital de imagens pelo método supervisionado, para o qual se definiu amostras de treinamento para cada uma das classes considerando que a área era conhecida. As técnicas de classificação de imagens digitais buscam o reconhecimento automático de alvos, em função de determinado critério de decisão, sendo agrupado em classes os alvos que apresentam similaridade em suas respostas espectrais.

Segundo Nascimento et al. (2016) nesse método de classificação o analista tem de conhecer a área de estudo para que possa selecionar as amostras de treinamento que sejam representativas. Fitz ressalta que a classificação supervisionada diz respeito ao método que faz uso da capacidade interpretativa do técnico, assim uma imagem será classificada com base em determinados parâmetros definido pelo profissional que, necessariamente, deverá ter conhecimento das características da área de trabalho. Foram selecionadas também amostras de teste, que tem por objetivo medir a acurácia das amostras de treinamento e do resultado.

Existem vários métodos para realizar a classificação das imagens, neste sentido foram aplicados três métodos para a referida classificação supervisionada: O primeiro foi o método do paralelepípedo que, segundo Fitz trabalha com uma área quadrada representativa, definida pelo menor e maior valor de pixels contidos em um agrupamento pré-escolhido. Nesse método se o valor do pixel cair acima do limiar inferior e abaixo do limiar superior para as $\mathrm{n}$ bandas que estão sendo classificadas, ele é alocado àquela classe (MENESES et al., 2012). Porém, o mesmo autor ainda ressalta que é comum nesse método que no processo de classificação ocorrer pixels que sejam candidatos a várias classes ou que não se encaixam a nenhuma classe. O segundo, o método da distância mínima, emprega bases estatísticas para sua execução; o método se utiliza da medida de distância Euclidiana de cada pixel à média de cada agrupamento (MENESES et al., 2012).

Conforme Fitz, esse método trabalha no sentido de atribuir a cada pixel da imagem um determinado valor, conforme a classe mais próxima dele. O terceiro, o método da distância máxima verossimilhança (MaxVer), baseia-se na escolha de áreas que possam ser representativas de determinadas feições conhecidas, são utilizadas a média e a covariância dos pixels amostrados, sendo calculada a probabilidade de um pixel externo a essas amostras pertencer a elas. No método MaxVer assume-se que todas as bandas têm distribuição normal e calcula a probabilidade de um dado pixel pertencer a uma classe específica (INPE, 2008).

A estatística Kappa foi o método utilizado para avaliar a concordância entre a verdade terrestre com o mapa temático. A grande vantagem do uso da estatística Kappa é que no cálculo do coeficiente se incluem todos os elementos da matriz de erro e não somente os elementos da diagonal principal, como no caso da 
exatidão global (OLIVEIRA et al., 2011). Segundo Kotz (1983) o Coeficiente Kappa pode ser definido como uma medida de associação usada para descrever e testar o grau de concordância (confiabilidade e precisão) na classificação, na Tabela 1, estão descritos as faixas de classificação do índice Kappa.

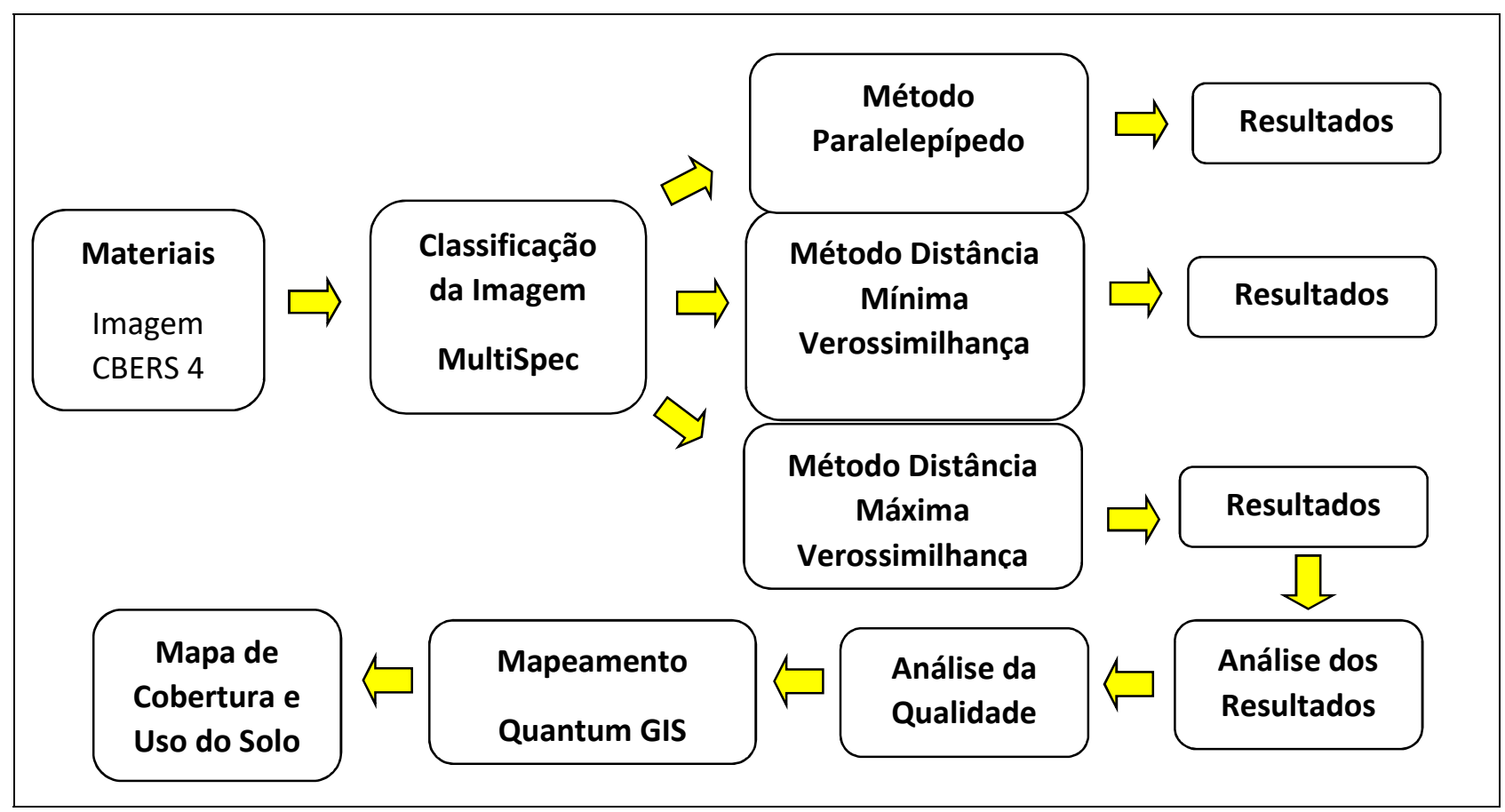

Figura 2: Resumo das etapas desenvolvidas.

Tabela 1: Faixa de classificação do Índice Kappa.

\begin{tabular}{|l|l|}
\hline Coeficiente Kappa & Classificação \\
\hline$<0,00$ & Ruim \\
\hline $0,00-0,20$ & Fraco \\
\hline $0,21-0,40$ & Razoável \\
\hline $0,41-0,60$ & Boa \\
\hline $0,61-0,80$ & Muito Boa \\
\hline $0,81-1,00$ & Excelente \\
\hline
\end{tabular}

Conforme Cecconello et al. (2017), cabe salientar que a exatidão global varia de 0 a $100 \%$, sendo obtida pela razão entre o número de pixels concordantes (diagonal principal da matriz de confusão) e o total de pixels classificados. Para confecção dos mapas de uso e ocupação dos solos, utilizou-se como base as cores indicadas no Manual Técnico de Uso da Terra (IBGE, 2013) conforme tabela 2 para as classes pré-definidas. A classe vegetação exótica muitas vezes é considerada espécie invasora, por não pertencer a flora da região, mas neste caso estão relacionadas com o cultivo de espécies de eucalipto e acácia negra para exportação. A Classe Vegetação Nativa é o conjunto de espécies ou plantas que se encontram em determinado local, desde que haja condições para seu desenvolvimento e pelo fato da cidade estar as margens do Rio Camaquã possui remanescentes deste tipo de vegetação. A classe Solo Exposto pode ocorrer após a retirada da vegetação, contribuindo para o enfraquecimento do solo, no caso desta classificação o solo exposto está diretamente relacionado a areia oriunda de barras de sedimento no leito do Rio Camaquã. A Classe água está presente em sua maioria no Rio Camaquã e também em barragens ou açudes utilizados na agricultura. A classe campo/agricultura é a base do município sendo a principal atividade na zona rural. 
Tabela 2: Cores conforme manual técnico de uso da terra.

\begin{tabular}{|l|l|l|l|}
\hline Classe & Uso e Cobertura do Solo & RGB & Composição RGB \\
\hline 1 & Vegetação Exótica & $205,173,0$ & \\
\hline 2 & Vegetação Nativa & $115,168,0$ & \\
\hline 3 & Solo Exposto & $178,178,178$ & \\
\hline 4 & Água & $153,194,230$ & \\
\hline 5 & Campo/Agricultura & $255,214,0$ & \\
\hline
\end{tabular}

\section{RESULTADOS E DISCUSSÃO}

Como resultado dos trabalhos foram elaborados três mapas, em três diferentes métodos, sendo o primeiro método do paralelepípedo, o segundo, método da distância mínima verossimilhança e o terceiro, método da distância máxima verossimilhança com a finalidade de verificar quantitativamente a porcentagem do uso do solo na região de estudo a partir das classes temáticas definidas no trabalho, seguem elas: vegetação exótica, vegetação nativa, areia, água e campo/agricultura.

Segundo Pereira (2011) para que uma classificação seja considerada de boa aceitação, o índice de exatidão global (acurácia) precisa ser maior ou igual a 85\%. A estatística Kappa é um método utilizado para avaliar a concordância entre a verdade terrestre com o mapa temático obtido a partir da interpretação de dados de satélite. Após as classificações nos três métodos propostos encontrou-se os seguintes resultados conforme tabela 3 .

Tabela 3: Resultados após classificação.

\begin{tabular}{|l|l|l|}
\hline \multicolumn{1}{|c|}{ Métodos } & \multicolumn{2}{c|}{ Qualidade } \\
\hline \multirow{2}{*}{ Método Paralelepípedo } & Kappa & $58,3 \%$ \\
\cline { 2 - 3 } & Exatidão Global & $65,8 \%$ \\
\hline \multirow{2}{*}{ Método Distância Mínima Verossimilhança } & Kappa & $71,5 \%$ \\
\cline { 2 - 3 } & Exatidão Global & $77,5 \%$ \\
\hline \multirow{2}{*}{ Método Distância Máxima Verossimilhança } & Kappa & $92,3 \%$ \\
\cline { 2 - 3 } & Exatidão Global & $93,9 \%$ \\
\hline
\end{tabular}

A classificação no método de paralelepípedo obteve um desempenho muito baixo conforme figura 3, resultando o índice Kappa em apenas 58,3\% e exatidão global de 65,8\%. Neste método houve grande confusão entre vegetação nativa e vegetação exótica, onde 1520 de 1932 pixels foram classificados como vegetação exótica, 1895 de 2157 pixels foram classificados como vegetação nativa e 205 de 1801 pixels foram classificados como lavoura e que na verdade pertenciam a outras classes.

A classificação no método da distância mínima verossimilhança, obteve um resultado pouco melhor do que o método de paralelepípedo conforme figura 4. Nesta classificação obteve-se índice Kappa de 71,5\% e exatidão global de 77,5\%, resultando erro de 41\% na classe de vegetação exótica, ou seja, 792 de 1932 pixels classificados como vegetação exótica, pertencem a classe de vegetação nativa. Na classe de vegetação nativa houve erro de 19.4\%, ou seja, 413 de 2157 pixels foram classificados como vegetação nativa e pertencem a classe de vegetação exótica. Já a classe de campo/agricultura teve erro de $47.1 \%$, sendo que 485 de 1801 pixels classificados como campo/agricultura pertenciam à classe de vegetação exótica e 345 de 1801 pixels pertenciam à classe de vegetação nativa. 


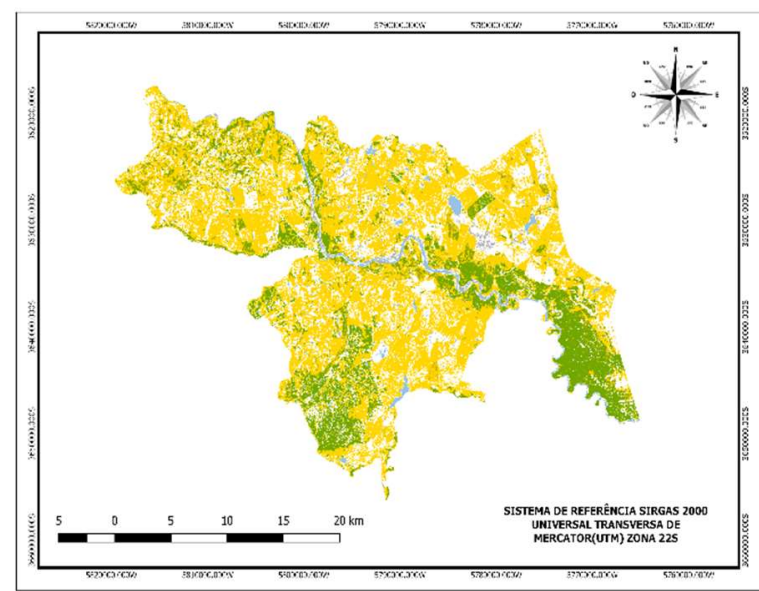

Figura 3: Classificação pelo método paralelepípedo.

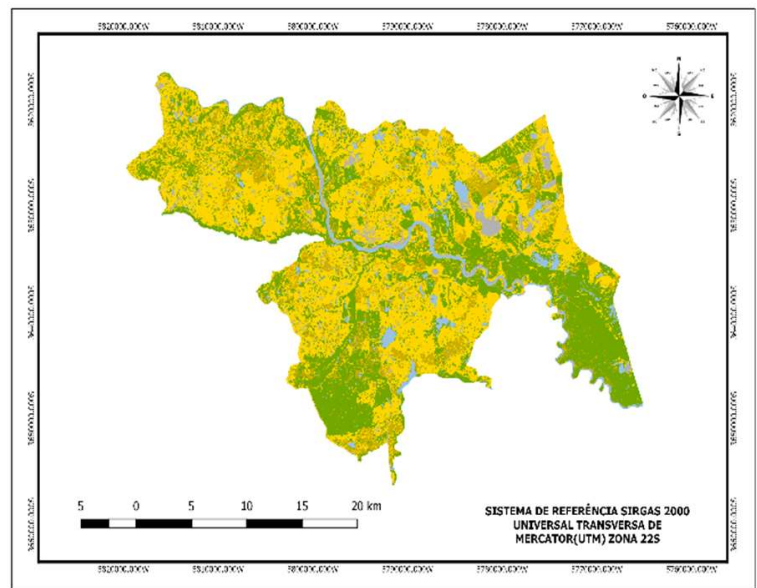

Figura 4: Classificação pelo método da distância mínima verossimilhança.

De acordo com os resultados obtidos com o método da distância máxima verossimilhança conforme figura 5, obteve-se índice Kappa excelente com 92,3\% e exatidão global de 93,9\%, entretanto, as matrizes de confusão mostram que para a classe vegetação exótica obteve-se um erro de 9,9\%, ou seja, 167 de 1932 pixels que foram classificados como vegetação exótica eram pertencentes a outra classe, no caso vegetação nativa. Para a classe vegetação nativa encontrou-se erro de 6,3\%, ou seja, 107 de 2157 pixels classificados como vegetação nativa pertenciam à classe vegetação exótica. A classe campo/agricultura resultou no maior percentual de erro, 12,5\%, onde 167 de 1801 pixels classificados como campo/agricultura pertenciam à vegetação nativa e 59 de 1801 pixels pertencem à vegetação exótica.

A Exatidão Global da classificação digital, expressa pela razão entre os pontos corretamente classificados e o total de pontos de referência, calculado em 93,9\%, está acima do patamar mínimo de 85\% estabelecido por Jensen (1986). O valor do coeficiente Kappa obtido de 92,3\%, menor do que a Exatidão Global, justifica-se pelo fato de o índice Kappa considerar todas as células da matriz de erros. Também se realizou o processo de fotointerpretação da imagem original e a imagem classificada verificando que o resultado é compatível com a verdade de campo. Após classificação, calculou-se as áreas em hectares cujo resultado é apresentado na tabela 4.

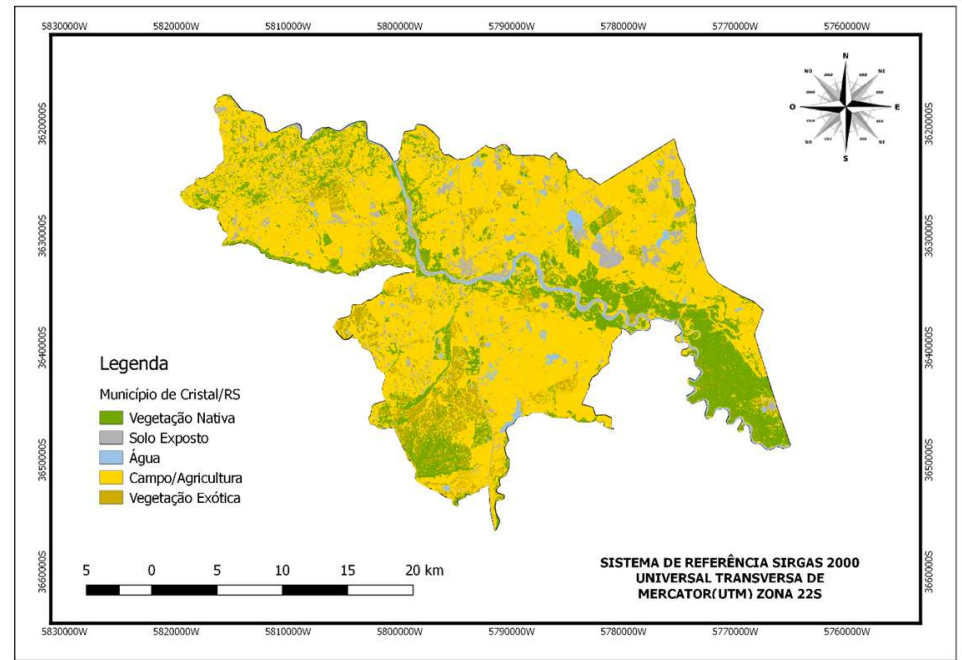

Figura 5: Classificação pelo método da distância máxima verossimilhança 
Tabela 4: Quantificação das diferentes classes em hectares.

\begin{tabular}{|l|l|}
\hline \multicolumn{1}{|c|}{ CLASSES } & \multicolumn{1}{c|}{ ÁREA (ha) } \\
\hline Vegetação Exótica & $\mathbf{4 1 8 0}$ \\
\hline Vegetação Nativa & 13025 \\
\hline Solo Exposto & $\mathbf{4 2 8 8}$ \\
\hline Água & 1963 \\
\hline Campo/Agricultura & $\mathbf{4 5 8 1 9}$ \\
\hline
\end{tabular}

No Município de Cristal estão instaladas duas grandes empresas no ramo de plantio e extração de espécies exóticas, sendo elas eucalipto e acácia negra. Essas áreas foram bem delimitadas na figura 5, e corroboram com os resultados quantitativos da classificação da classe de vegetação exótica que apresentou o total de 4180 ha representando 6,03 \% dá área do município. A distribuição dessa classe aparece nas zona sul do município de forma aglomeradas, áreas utilizadas para plantio pelas empresas, e algumas áreas mais dispersas ao longo de todo o território que são plantios particulares ou de regeneração natural ou invasora. Na figura 6, apresentamos uma foto com um exemplo desta classe.

O Município de Cristal está inserido na bacia hidrográfica do Rio Camaquã, o município é margeado por este rio, a presença da classe de Vegetação nativa está diretamente relacionada a mata ciliar do rio Camaquã e seus afluentes, esta classe conforme classificação apresenta um total de 13025 ha. Na figura 7, podemos observar a mata ciliar do rio Camaquã em Cristal que abrange 18,80 \% da área total do município.

O Rio Camaquã possui um grande problema que é o assoreamento, a classe solo exposto está diretamente ligada a este fato, formando as chamadas 'barras de sedimento', possui 4288 ha desta classe, representando 6,18 \% dá área do município, o assoreamento de um rio pode ser provocado principalmente pelo uso e ocupação indevido do solo. Na figura 8, é demonstrado exemplo do solo exposto.

O Município de Cristal tem sua economia voltada à agricultura, a classe campo/agricultura possui 45819 ha, ou seja, 66,14 \% do município, sendo que está classe é composta principalmente com as culturas de arroz, soja e nas pequenas propriedades as culturas de milho e fumo (Figura 9). Já a classe água possui 1963 ha, 2,83 \% da área de Cristal, que é resultado de construções de açudes para dessedentação animal e utilizados para irrigação de culturas, e também pelo fato do município ser margeado pelo Rio Camaquã (Figura 10).

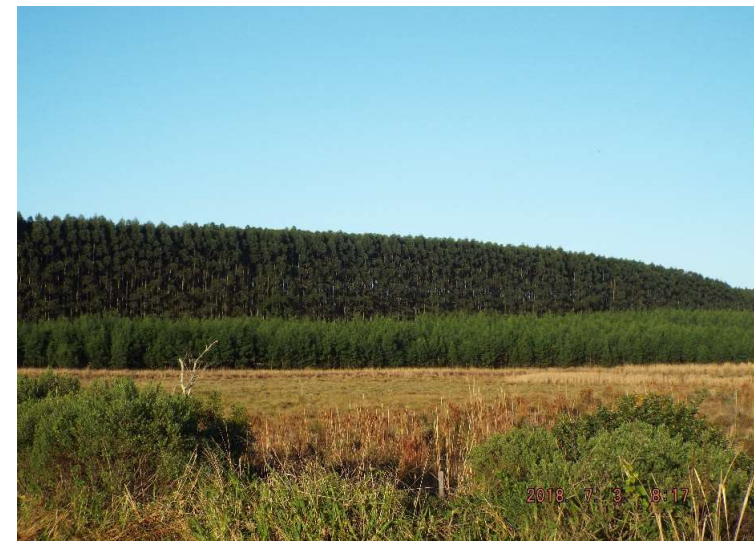

Figura 6: Imagem do plantio de espécies exóticas na cidade de Cristal/RS

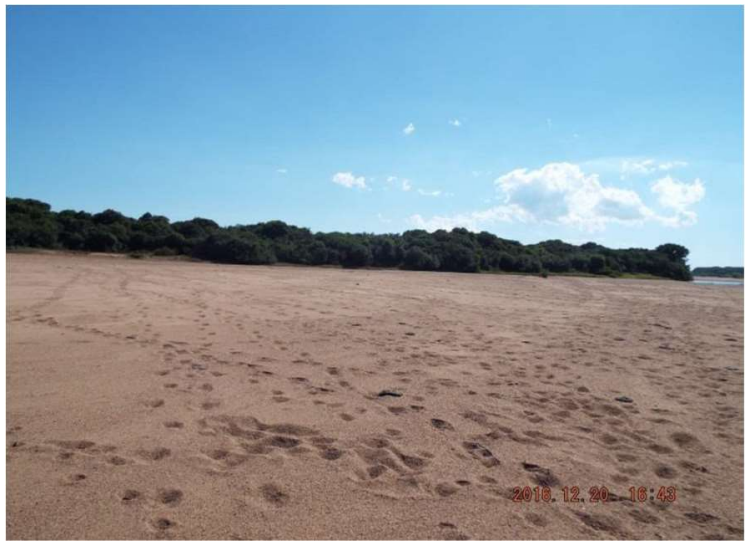

Figura 7: imagem da mata ciliar nativa na cidade de Cristal/RS. 


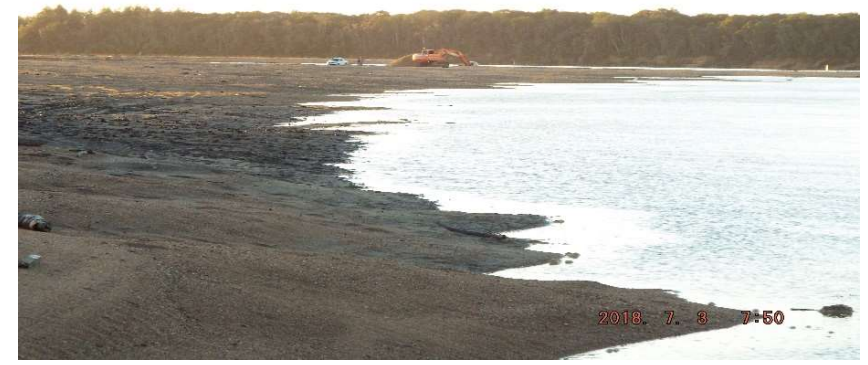

Figura 8: imagem solo exposto no Rio Camaquã na cidade de Cristal/RS.

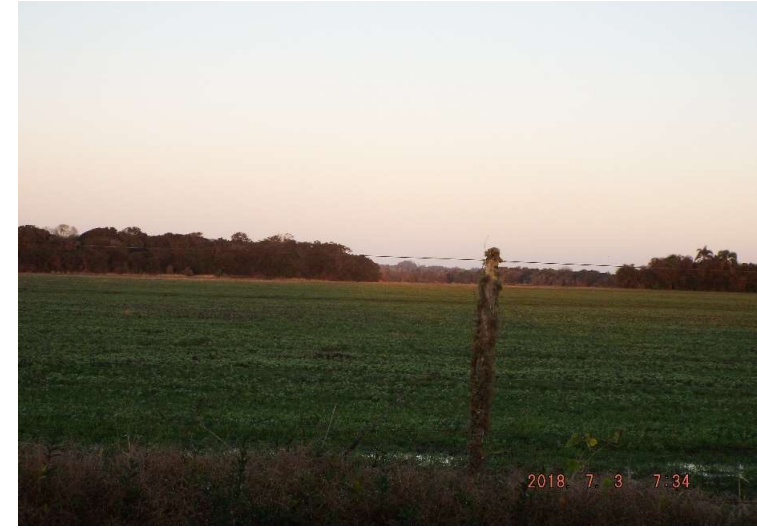

Figura 9: imagem classe campo/agricultura na cidade de Cristal/RS.

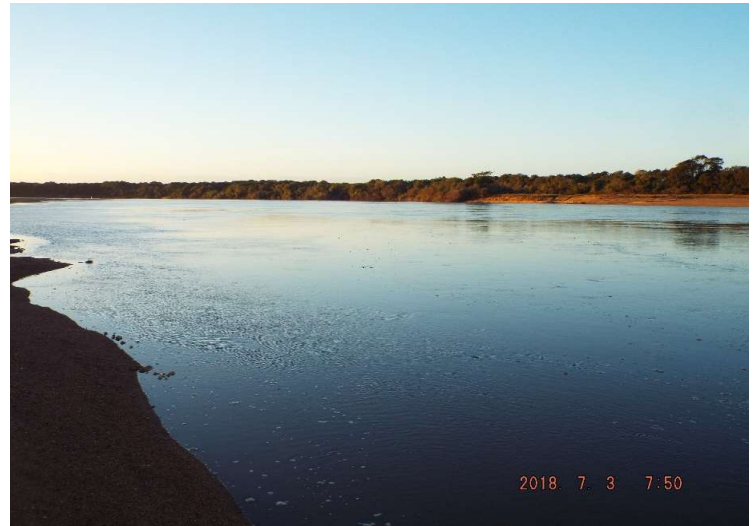

Figura 10: imagem classe água no Rio Camaquã na cidade de Cristal/RS.

\section{CONCLUSÕES}

Com o conhecimento das áreas do município através da utilização de softwares livres podemos afirmar que o uso das geotecnologias é essencial para subsidiar o planejamento municipal e ambiental com um custo baixo ou até mesmo sem custos. Ainda hoje, na maioria das prefeituras os setores de planejamento e meio ambiente ainda trabalham com mapas impressos ou mapas em formatos DWG (autocad), tanto para cadastro como bases para elaboração de projetos e tomada de decisão referente a aprovação destes, estas bases as vezes não estão sequer georreferenciadas. Assim a utilização das geotecnologias pode elevar o acervo de dados com dados atualizados dos seus municípios, podendo disponibiliza-los para o público em geral, sendo eficaz e transparente.

Apesar destas vantagens, ainda não é comum nos órgãos públicos a utilização destas ferramentas, as vezes por falta de informação ou pelo simples fato da resistência a mudanças. Estas ferramentas quando utilizadas para o planejamento ajuda aos técnicos de diversos órgãos a embasar suas decisões, tendo assim maior segurança e certeza das decisões a serem tomadas, seja elas em aprovação de projetos de engenharia, decisão referente a qualquer empreendimento que necessite de licenciamento ambiental ou até mesmo análise de dados para obras públicas, para analisar a viabilidade.

Para realizar uma gestão adequada devemos conhecer o município, com o conhecimento e utilização das geotecnologias podemos elaborar mapas para que tenhamos segurança e eficácia na gestão pública, auxiliando em tomadas de decisão com embasamento técnico. O método que demonstrou com maior confiabilidade e o produto gerado corresponde fidedignamente a realidade do município de Cristal nas 
classificações foi o da distância máxima verossimilhança, gerando subsídios para planejamento e análise ambiental.

\section{REFERÊNCIAS}

ALVES, H. P. F.. Análise dos fatores associados às mudanças na cobertura da terra no Vale do Ribeira através da integração de dados censitários e de sensoriamento remoto. Tese (Doutorado) - Universidade Estadual de Campinas, Campinas, 2004.

\section{CÂMARA, G.; MEDEIROS, J. S.. Geoprocessamento para} projetos ambientais. Tutorial. São José dos Campos: Instituto Nacional de Pesquisas Espaciais, 1998.

CAMARGO, F. F.; ALMEIDA, C. M.; COSTA, G. A. O. P.; FEITOSA, R. Q.; OLIVEIRA, D. A. B.; HEIPKE, C.; FERREIRA, R. S.. An open source object-based framework to extract landform classes, v.39, n.1, p.541-554, 2012.

CRISTAL. Lei municipal n.1238: Dispõe sobre o parcelamento do solo urbano e dá outras providências. 2011.

CRISTAL. Plano Municipal de Saneamento Básico. Cristal, 2011b.

CRISTAL. Plano Ambiental Municipal. Cristal, 2008.

FLORES, C. A.; FASOLO, P. J.; POTTER, R. O.. Solos: levantamento semidetalhado. In: FALCADE, I.; MANDELLI, F.. Vale dos Vinhedos: caracterização geográfica de região. Caxias do Sul: EDUCS, 1999.

RODRÍGUEZ, R. G.. Análisis de imágenes satelitales para la evaluación del seguimiento temporal de la urbanización del territorio. Tese (Doutorado), 2018.

INPE. Instituto Nacional de Pesquisas Espaciais. Manuais: tutorial de geoprocessamento SPRING. 2008.

IBGE. Instituto Brasileiro de Geografia e Estatística. Manual técnico de uso da terra. 3 ed. Rio de Janeiro, 2013.

IBGE. Instituto Brasileiro de Geografia e Estatística. Censo 2010. 2010.

JENSEN, J. R.. Sensoriamento Remoto do Ambiente: uma perspectiva em recursos terrestres. 2 ed. São José dos Campos: Parêntese, 2011.

JENSEN, J. R.. Introductory digital image processing. Englewood Cliffs: Prentice Hall, 1986.

JULIÃO, R. P.. Guia metodológico para a cartografia de risco: um produto do diálogo ciência/utilizadores. Realidades e desafios na gestão dos riscos: diálogo entre ciência e utilizadores. Núcleo de Investigação Científica de Incêndios Florestais - Nicif. Coimbra: Imprensa Universidade de Coimbra, 2014

KOTZ, S, J. N. L.. Encyclopedia of statistical sciences. New York: John Wiley \& Sons, 1983.

LANDGREBE, D.; BIEHL, L.. An Introduction \& Reference for MultiSpec@C. West Lafayette: Purdue Research Foundation, 2011.

MENESES, P. R.; ALMEIDA, T. D.. Introdução ao processamento de imagens de sensoriamento remoto. Brasília: UnB, 2012.

NASCIMENTO, I. S.; CRUZ, C. B. M.; NEVES, S. M. A. S.; GALVANIN, E. A. S.. Avaliação da exatidão dos classificadores MaxVer e ISO cluster do software Arcgis for desktop, com uso de imagem LANDSAT 8 do município de Cáceres/MT. Revista Continentes, Rio de Janeiro, v.5, n.8, p.48-62, 2016.

OLIVEIRA, F. G.; SERAPHIM, O. J.; GURGEL, E. M. Comparação de métodos de classificação na análise do uso e cobertura do solo. In: CONGRESSO BRASILEIRO DE ENGENHARIA AGRÍCOLA, 40. Anais. 2011.

PEREIRA, R. M.. Comparação entre os métodos de classificação supervisionada MaxVer e distância mínima na análise do uso e cobertura do solo na região do alto Araguaia. In: JORNADA DE PESQUISA E PÓS-GRADUAÇÃO E SEMANA NACIONAL DE CIÊNCIA E TECNOLOGIA UNIVERSIDADE ESTADUAL DE GOIÁS, 6. Anais. QGIS, 2011.

PESSOA, L. C.; REIS FILHO, A. A.; ROCHA, J. V. V.. O cadastro territorial multifinalitário como ferramenta no planejamento urbano. Brazilian Journal of Development, v.5, n.1, p.915926, 2018.

STEINIGER, S.; HAY, G. J.. Free and open source geographic information tools for landscape ecology. Ecological Informatics, v.4, n.4, p.183-195, 2009.

CECCONELLO, S. T.. análise ambiental dos processos dinâmicos do uso e Cobertura da terra sobre as áreas de preservação Permanente no município de pelotas entre os anos de 1985 e 2015. Dissertação (Mestrado em Desenvolvimento Territorial e Sistemas Agroindustriais) Universidade Federal de Pelotas. 2017.

A CBPC - Companhia Brasileira de Produção Científica (CNPJ: 11.221.422/0001-03) detém os direitos materiais desta publicação. Os direitos referem-se à publicação do trabalho em qualquer parte do mundo, incluindo os direitos às renovações, expansões e disseminações da contribuição, bem como outros direitos subsidiários. Todos os trabalhos publicados eletronicamente poderão posteriormente ser publicados em coletâneas impressas sob coordenação da Sustenere Publishing, da Companhia Brasileira de Produção Científica e seus parceiros autorizados. Os (as) autores (as) preservam os direitos autorais, mas não têm permissão para a publicação da contribuição em outro meio, impresso ou digital, em português ou em tradução. 